\title{
The Universe, Origen and Destiny
}

\author{
Juan L. Lartigue \\ UNAM, México City, México \\ Email: jmlg5@hotmail.com
}

How to cite this paper: Lartigue, J.L. (2018) The Universe, Origen and Destiny. Journal of Modern Physics, 9, 1814-1826. https://doi.org/10.4236/jmp.2018.99115

Received: June 19, 2018

Accepted: August 12, 2018

Published: August 15, 2018

Copyright $\odot 2018$ by author and Scientific Research Publishing Inc. This work is licensed under the Creative Commons Attribution International License (CC BY 4.0).

http://creativecommons.org/licenses/by/4.0/

\begin{abstract}
In a previous paper [1] [2] [3], the author has proposed the following concepts: the Hubble field, the constant value of acceleration of the Universe expansion, a De Sitter-Hubble gravitational equation, and the possibility of an imaginary time, all of them mainly oriented to a hypothesis about the Universe destiny. This work mentions some theories about the origin of the Universe and suggests the existence of a limit for the physical Universe. Accordingly to a relevant author [4], there are two main ways in considering these themes: those methods based on physical theories and those founded in metaphysical concepts of philosophy and religion. After some comments on such theories, this paper agrees that, in the physical search, the Big Bang seems to be the most probable origin of the physical Universe, space and time. On the metaphysical approach, the creation ex nihilo seems to be the commonest hypothesis for such origin. Besides, it is assumed that the Creator would have set two driving and successive conditions: transcendence and ethics. Reference is made to the arrow of time and to the proper time, a physical concept aimed to define both frozen and imaginary times, which would correspond to a space without time, and another space with imaginary time. A diagram is proposed for the Euclidic space, including a world-line throughout the space-like.
\end{abstract}

\section{Keywords}

Hubble Field

\section{The Ancient Cosmologies}

In the oldest religions and philosophies, the origin of the Universe was attributed to divinities. Five relevant examples are the following:

1) The pharaonic period of Egypt from (VI B.C.) to (I A.C.) centuries. Its cosmology assumed that, initially, there existed only the Nun, identified as the nothingness, though it contained a Demiurge who, finally, did create the Un- 
iverse. Besides, there existed the god Nether, who was rather assumed as having a cosmic function [5].

2) The Toltec religion ( $\mathrm{X} \mathrm{b}$. C.) had not many gods; it just assumed the existence of a supreme divinity as the creator of the Universe (Figure 1), an unnamed and amorphous entity who is invisible and powerful, some deity of the art of "living in equilibrium"; it was represented, much later, by the cyclic feathered snake figure (Quetzalcoatl). Unfortunately, the internal wars and the external conquest caused losses of main relics [6].

3) The Genesis, written about (X b. C.) states that the creation of the Universe was decided by God and being made by periods. Tributary religions to that cosmology are Judaism, Christianity and the Islam.

4) The ancient Greek philosophers had any cosmological approach. Aristotle (IV b. C.) and other eminent Greek philosophers were strongly adhered to the geocentric hypothesis, at such an extent that the later heliocentric model, proposed by Aristarchus, remained out of their reach for a long time. Incredibly, Ptolomeus developed a big work to locate more than one thousands of stars (II a. C.) and he wrote a metaphysical text (Almagesto); by that time, Euclid stated the principles of Geometry that has been the basis for modern scientific theories. The Greek religion was always polytheist, with Zeus as the main divinity. Yet, it must be said that the Aristotle principle about "the first cause" or prime motor was the basis for creationism in subsequent religions, like Aquinas's doctrine in the catholic theology [7].

5) The Roman Empire inherited the Greek culture, including the Pantheon of Gods. However, both Romans and Greeks had a common adoption (II a. C), the Iranian deity Mithras, who was assumed to be the creator of the Universe; that belief began to decline at the time of Constantine [8].

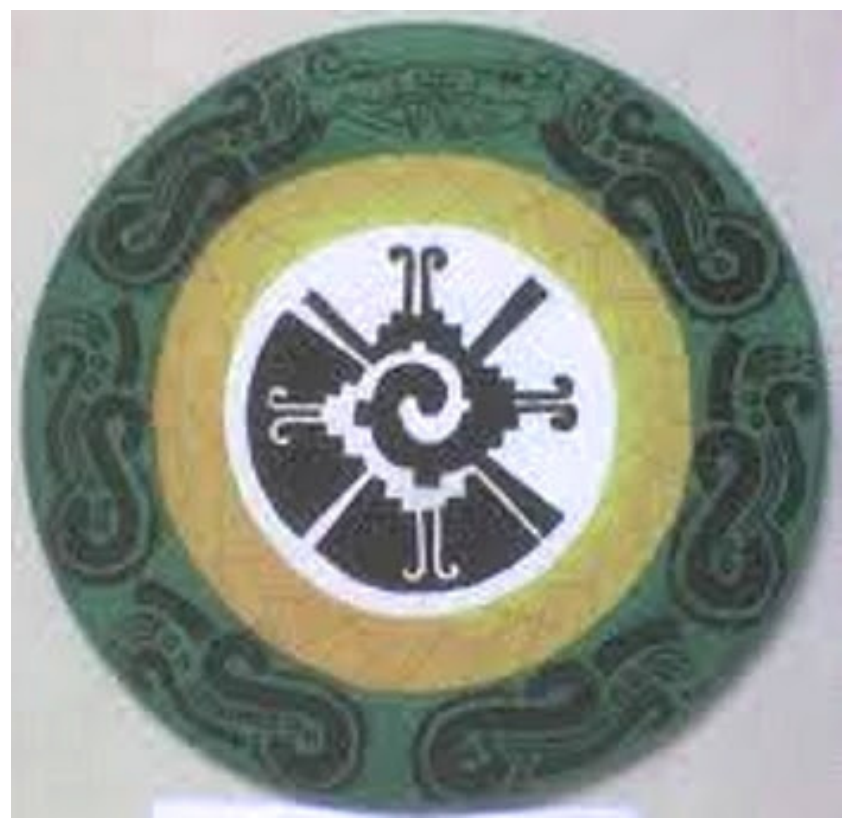

Figure 1. The toltec universe [9]. 


\section{Cosmology in the Middle Ages and Renaissance}

In these epochs Cosmology had an important development, founded initially on Religious beliefs, based after on scientific criteria that were often faced to a church opposition.

1) The Islam religion was founded by Mahoma (575-632). His God, Alá, is the origin and creator of the Universe.

2) In the Middle Ages, the physical Cosmology made almost no progress because of Catholic Church opposition (Figure 2) [9]. Search was cautiously oriented to Astronomy as it occurred with the works of the Greek Ptolomeus (II A.C.), whose books, such as Almagesto, were adopted by astronomers of the Middle Age and translated to the Arab, so arriving to a final version by Al-Magisti [10].

3) Saint Agustin de Hipona (Algery, 354-430) mentions three themes in his Theodicea: the third one was the Creation problem" where he declares that "man has three properties: memory, understanding and intention, which correspond to the tree persons of the Trinity" [11].

4) In Italy, the astronomer G. Bruno (XVI a. C.) did conceive a Universe which is infinite in size and time. Besides, he said that it could exist some inhabited worlds in the universe, an assertion that took him to death.

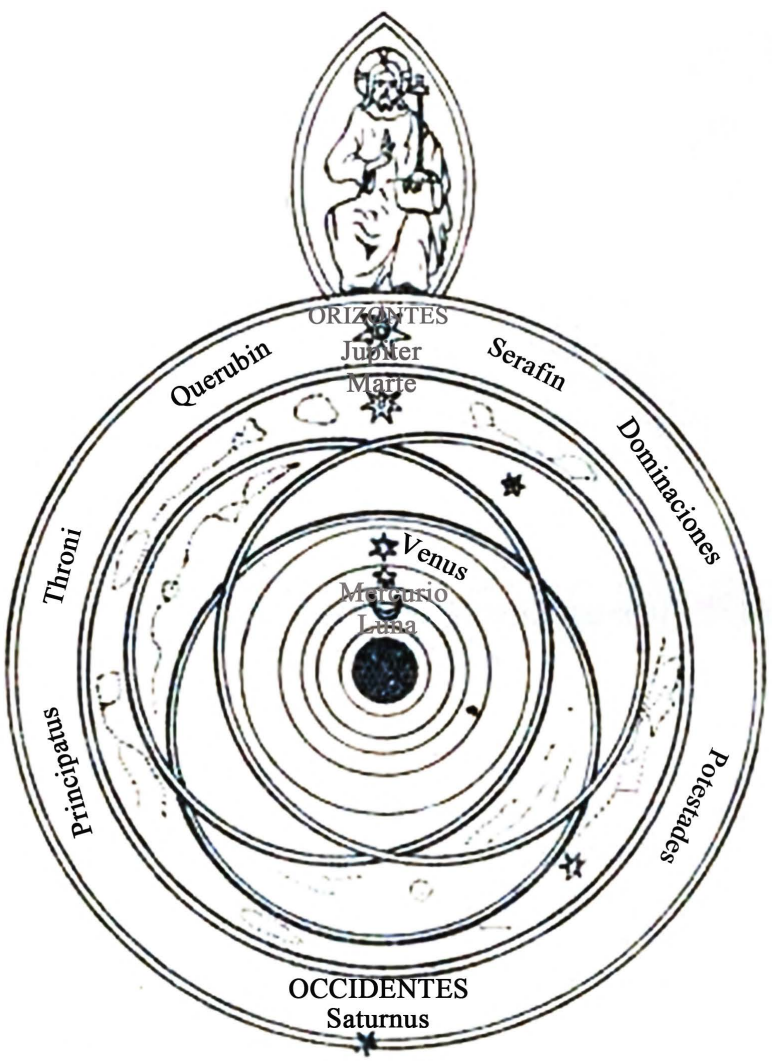

Figure 2. The universe in the middle age [9].

${ }^{1}$ Dios creó al mundo según modelos que son las ideas inmutables y eternas que existían en la mente del creador. 
5) N. Copernicus and G. Galilei (The Father of Science, XVI a. C.) remained loyal to the heliocentric theory; their works in Astronomy and Physics have exerted a long-standing influence, yet though their ways of thinking were the objects of dispute with the Church [12].

6) J. Kepler (1571-1630) and Tycho Brahe were two important astronomers. The three laws of Kepler are basics in Astronomy, thanks to the support of Tycho Brahe [13].

7) I. Newton (1642-1772), the greatest astronomer and natural philosopher of the Renaissance, was born in England. He assumed a static yet infinite Universe and deduced three basic laws of mechanics as well as the equation of gravitational attraction [14].

8) R. Descartes (1596-1650), a French philosopher and scientist, considered to be the father of Modern Philosophy [15]. He was the founder of Rationalism ("I think, so I exist") and wrote that "God is the only cause of events". He worked many topics, including the Cartesian coordinates.

9) S. Laplace (1749-1827) did work in the mathematical field with Lagrange and developed the transform between real and imaginary variables. In his "System of the World", he proposed a nebular theory for the origin of the Universe [16].

\section{Modern Cosmologies}

After the period of development of the today known as classical physics and cosmology, the XIX and XX centuries were specially rich in the arise of new theories on these and related topics such as: modern mathematics, experimental tools, chemistry, thermodynamics, astronomy and the theory of relativity. A brief review of the last one follows.

1) A. Einstein (1879-1955), a German scientist, he was the creator of the Theory of Relativity (Special in 1905 and General in 1915). He developed many new physical concepts and obtained the Nobel Prize due to his work on the photoelectric effect. It must be pointed out that Einstein was based on the works of Geometry of Euclide, Lorentz, Riemann, Minkowski, and Lobachewski, as well as on eventual communication with other scientist such as Poincaré, Sommerfeld, and Weyl. The Special Theory is aimed to demonstrate the relativity of movements and times as functions of the reference frames, i.e. the relative velocities of masses and observers; so, he defined the transcendental concept of proper time. After the Special Theory, Einstein tried to incorporate the acceleration factor; then, he developed the space-time concept and replaced the Newtonian definition of force by the space-time curvature, i.e. "Space-time tells mass how to move and mass tells space-time how to curve" [17]. His gravitational equation has two terms: the left one refers to space-time as a function of the metric; the right one expresses the energy and momentum in the Universe. Einstein field equations gave not static but dynamical solution; so, to obtain a static one according to his own time, he introduced a cosmological constant, $\Lambda$ in the left side. In that concerning, Einstein did assume a not-expanding Universe and he 
maintained such a view till knowing the A. Friedmann and E. Hubble discoveries.

2) W. De Sitter (1872-1934). A German physicist. He worked with Einstein in 1932 though he later modified the former's gravitational equation by assuming a Universe empty of matter and energy [18]; so, he cancelled the right side of the equations, probably based on the low density of the Universe.

3) A. Friedmann (1888-1925). A Russian mathematician and meteorologist who proposed to eliminate the $\Lambda$ parameter of Einstein, in two new basic cosmological equations. A problem with one of them was that it affords negative values for the Universe acceleration [1]. Besides, he introduced the curvature parameter in a later form of the RWFL equation [19].

4) G. Lemaitre (1889-1934). A Belgian priest, he was the first in predicting the Universe expansion and calculating a very important parameter value in 1927, two years before than Hubble's confirmation. Lemaitre was also the first one proposing the primeval atom as the origin of the Big Bang, so called by Gamow in 1942. Besides, he cooperated with several scientists in defining new concepts, as the coordinate system of RWFL, necessary to study several Cosmological models [20].

5) E. Hubble (1889-1953) was an American astronomer who provided many fresh concepts to modern Cosmology. He showed that some distant nebula were galaxies in fact. Based on the variable luminosity of the cepheids, he determined distances [21] and velocities between them, and, finally, he deduced his famous law that includes the very important parameter $\mathrm{H}\left(\mathrm{s}^{-1}\right)$.

\section{Recent Cosmological Theories}

Several cosmological theories have been developed after those of Einstein, Friedmann, and Lemaitre. Some of them are the following:

1) The static Universe model, equivalent to those of the Greek geocentric philosophy age and subsequently to the Middle Age beliefs, developed many centuries later. As mentioned above, the main trouble for Einstein was the acceptance of the Universe expansion.

2) E. Milne (1896-1950) proposed a Universe having infinite time and size, the Static Universe theory, which had many critics [22].

3) In 1948 some theories of the Steady State [23] Universe, as those of Bondi, Gold, Hoyle and Narlikar, among others, reappeared. Theirs were not a Static Universe since it may grow. This theory does not accept the Big Bang, yet it assumes the constancy of the Universe density; so it concerns to a continuous creation of matter. After the general acceptation of the Cosmic Background Radiation and the Universe expansion, the Steady State theory was discarded.

4) The $\Lambda$ theory, intended to justify a static Universe, was finally rejected by Einstein about 1931, after knowing the Hubble discovery. However, the $\Lambda$ sign has been taken again by new cosmologists to show a theory that would result opposed to Einstein's original aim: it is that the Universe expansion has been originated by a mysterious dark energy [24]. 
5) A probably more realistic theory has been proposed by the author, in references [1] [3], based on the measurable Hubble parameter and a Hubble scalar field.

6) The favorite trending theory to combine general relativity with quantum mechanics is the super strings theory, whose results are not clear enough until now [25] [26].

\section{Additional Comments on the Scientific Theories}

In previous paragraphs they were mentioned the ancient beliefs (religious, philosophical and scientific) about the Universe creation. Additional comments on the scientific theories will be intended in the following section. In this respect, just two views thrive: the eternal Universe and the creation ex-nihilo.

1) The eternal existence of the Universe, as mentioned in paragraph (IV-2), has been sustained by some cosmologists. However, this model has been rejected because some facts are not accountable within the theory, i.e., the Cosmic Background Radiation and the already confirmed Universe expansion since, if it had an origin, it would correspond to a singularity.

2) There is the Conformal Cyclic Cosmology by R. Penrose, stating that the Big Bang singularity may occur after every aeon ( $\sim 10^{100}$ years). He applies a model based on the Second law of Thermodynamics and the Phase Space, to show that the last step of the Universe expansion should be formed by photons [27].

3) P. Teilhard de Chardin (1881-1955), a French priest. He was the founder of the Cosmic Theology and did argue that the Omega point stands for the maximum level of knowledge that human kind could reach at the end of the Universe. This theory was later developed by F. Tipler [28]. Both Chardin and Tipler kept concerned with the Universe destiny.

4) In respect to the creation ex-nihilo, there are still two options: the Big Bang and the Quantum Theory.

Regarding the later, reference [29] states that vacuum is not empty; its energy seems to be zero because it fluctuates between positive and negative energy; so, "the Universe emerged spontaneously from a random quantum fluctuation in a primordial vacuum"; M. Gleisser adds: "a scientific explanation to the origin of the Universe cannot be self-contained. Sometimes we must have the humility to accept that our modes of explanation have limits". The same reference mentions a S. Hawking conclusion: "The Universe came out of quantum nothingness, though the absolute nothingness is not scientific. That is the best that Science can do"'.

5) The opinion of J. Polkinghorne [31] about the Quantum Theory acceptance seems very interesting: "The discovery of Quantum Theory had produced the

${ }^{2}$ The final paragraph of Hawking's book expresses, in the Spanish translation [30]... "si descubrimos una teoría completa... comprensible para todos...entonces seremos capaces de tomar parte en la discusión de por qué existe el Universo y por qué existimos nosotros... sería el triunfo definitivo de la razón humana porque entonces conoceríamos el pensamiento de Dios”. 
deepest modification that Newtonian Physics had ever suffered... It was much more radical than that of the time relativity... Einstein was the last one of the ancients... his resistance to the modern quantum theory was a real loyalty to the older thinking forms". However, in spite of its success in Nuclear Physics, the Quantum Theory has not obtained acceptation equal to that of the Big Bang Theory respecting the cosmological origin of the Universe. Nevertheless, the extensive use of Quantum Theory in Nuclear Physics, in Chemistry and other sciences, has motivated big changes in the concept of the inherent incertitude of the micro and macroscopic measurements, as it were a generalization of the Heisenberg Principle. So, the original quantum singularity theory would still have something more to say.

6) Though the Big Bang has been universally accepted as the fittest cosmological theory (so, being accepted by the Catholic Church nowadays [32]), the cosmologist F. Hoyle had proposed some alternate models, probably originated in his own definition of religion as "escapism". He frequently uses the Democritus sentence: ex nihilo, nihil fit.

7) As it was said above respect to the Big Bang theory, G. Lemaitre proposed the first model of the Primeval Atom (1927), later named the Big Bang by G. Gamow (1942). Lemaitre's theory was soon confirmed by E. Hubble's discovery of the Universe expansion in 1929. It was in 1998 that reference [33] demonstrated the acceleration of this expansion. Reference [3] proposed in 2016 the constant value of such acceleration. These tests of Universe expansion, beside the already mentioned CRB and the matching chronology of nucleo-synthesis with the stars formation, make the Big Bang the most probable origin of the Universe and time. Besides, it works well with the Standard Model of Nuclear Physics. So, it may be assumed that, in the creation ex nihilo, the Universe and time started in a singularity (the Big Bang) i.e., the Universe (space, matter and time) had a common beginning; and space is expanding itself at a constant acceleration.

8) Associated to the Big Bang, there is the theory of creation continua, which assumes that Creation was not complete at the Big Bang and it continues forever. Many years before, Aquinas prevented on such idea when he wrote in (XIII a. C.) [7]: "The World process is dynamical, i.e. it implies changes though it does not create new things from nothing. Any created being may create nothing, absolutely. Only God can create and He did it already, at the beginning". The theory of creation continua coincides, partially, to that of paragraph (IV-3) of 'a steady state', which assumes a continuous creation of matter in order to maintain a constant density in the Universe. It should be, rather, a continuous change in the original matter.

\section{Metaphysical Aspects}

1) In his book on "The Spirit of God", P. Davies [34] wrote":

\footnotetext{
${ }^{3} \mathrm{~A}$ metaphysical interpretation is necessary to understand the Universe origin.
} 
After some concepts on the relevance of the Physical laws", he suggested that the "Cosmic Code" i.e. the set of all of the physical laws would have been created simultaneously to the Universe and, also, the idea that all of the physical laws could be unified in a unique mathematical order, i.e. the Theory of Everything.

2) Davies continues by asking: why has God decided to create the Universe?5.

In the French translation Davies states [34]: "Il me semble que, si l'on persévère avec le principe de raison suffisante... nous n'avons d'autre choix que de chercher une explication qui transcende le monde physique-dans quelque chose de métaphysique-parce que un Univers physique contingente ne peut renfermer en soi sa propre explication".

The frequent question about the instant when the Universe was created has been refuted by the assumption that time began along with singularity. Conjectures about a time before the Big Bang seem to be non-sense nowadays. Anyway, the imputed fate of God creating the Universe has not fully been explained to date. A cautious and preliminary attempt will be made in the following paragraphs.

3) Those assuming God as the creator of the Universe (that contents matter, space and time) have defined Him as an eternal, all-mighty, omnipresent and omniscient being. It seems that God happily existed in his own reign, free from any apparent need. Suddenly, He decided to create the Universe. Matter was so created in the form of very hot radiation (in the new space), so fulfilling a divine order to expand, cool and eventually condense itself in masses which must combine during indefinite time and under a pre-set of laws.

These laws induced matter to partially appear as radiations and masses such as the first elementary particles that evolved to form nuclei that reacted and added up to make big bodies, as stars, planets and galaxies. Later, by means of His own laws, God breathed life on Earth and also, by evolution processes, He printed some type of intelligence on his first_creatures. Accordingly to reference [7] the word "creation" has two meanings: the creation ex-nihilo and some transformations of matter at given times; (the best example would be the human concept pro-creation).

4) From Genesis [35], God said "that created was good" and also "Let us make the man at our image and similarity". So, by the above mentioned evolution, man was created along with a soul that includes the highest degree of intelligence which mankind has developed in its thriving to survive and understand his own origin as well as the God's will. In such a task, man has no other means than his own culture, religion and imagination. Such attempts have been always based on the already referred similarity between the man soul and God.

5) Why has God done so? The similarity between man and God is not referred, obviously, to the qualities of eternity or infinite wisdom, rather to the ${ }^{4}$ L'existence de régularités dans la Nature est un fait mathématique objectif. En revanche, les formulations dites lois, rencontrés dans les manuels scientifiques, sont des inventions humaines destinées à refléter des propriétés réelles de la Nature.

${ }^{5}$ S'il était satisfait d'être de toute éternité sans Universe, pourquoi a-t-il soudain décidé d'en créer un? 
so-called spirit that includes intelligence, conscience and free-will. Therefore, the man may dare to explore the possible answers to the big questions of the Universe origin and God's will. Such boldness is supposedly intended in this paper. The first question, that concerning to physical theories, has been answered enough in the twenty century by the Big Bang theorists. However, it lacks a hypothesis about the possible God's intentions in both subjects (transcendence and ethics) a hypothesis that would necessarily be similar to others generated by the human mind. So, a logical first reason would be a God's "programmed need" to apply, in a totally new way, the infinite magnitude of His own power. That may sound rare or absurd; however, it would be difficult to imagine a different cause for such a decision.

Genesis [35] says that, at the $6^{\text {th }}$ day, God had already created the Universe, the Earth and the vegetal and animal lives and He decided (rather, He had programmed), at the $7^{\text {th }}$ day, to create the human beings "at His own image and similitude", i.e. including immortal soul or spirit. So, in addition to life, two transcendent faculties He imprinted in humans (free-will and an ethical code), failed with the first couple. However, He decided to maintain such faculties for the future human kind, who is now applied to look for answers to the above mentioned questions.

6) God's intention in creating both the Universe and rational beings has been fairly discussed in previous paragraphs; pending is the other one and perhaps most difficult question in thinking through God's will. In addressing that, it is maintained the assumption that God's mind and that (infinitely lower) of humans are similar. So, it would be necessary to add some assumptions: after the free-will failure or sin of the first couple, God decided to print the code of ethics in the human kind, initially in the human's conscience and later reinforced by the Ten Commandments of the ancient Jewish religion (later adopted by tributary religions). So, both the spiritual transcendence and the ethics of the Creation would be self-evident for God's masterpiece: the human being. Yet, what could have been God's reasons for providing such endowments to humans (transcendence and ethics)? The concept of transcendence has implications for both: the future time and the human beings aware of such endorsement. The future time, that is, the promise, was anyway contained in God's redemptive plan: the human capacity to grasp God's message; however, ethics must be printed in human souls through the conscience and explicitly listed in the Ten Commandments or in the core beliefs of most of the ancient religions. As it is well-known, human history attests that God's will has been frequently ignored or misunderstood, rather than obeyed.

\section{The Time Limit}

Since the Big Bang, time had been passing, accordingly to Newton, with an apparent normal course during almost 15 billion years. It was in the Special Theory of Relativity that the time magnitude appeared as a function of the relative ve- 
locities of a mass and its observer. Then, a new term was coined: the proper time $\tau$, the time value recorded by one observer when he travels with a mass in a given trajectory, while another observer, at rest, records a "personal" time $t$ for that trajectory. As mentioned in reference [3], the relation between both times is: $\tau=$ $t / \gamma$, being $\gamma$ a function of the mass velocity ( $\mathbf{v}$ ) in such a way that, if $\mathbf{v}<\mathbf{c}$ (the velocity of light), $\tau>0$; if $\mathbf{v}=\mathbf{c}, \tau=0$; if $\mathbf{v}>\mathbf{c}, \tau$ becomes an imaginary number. In general, $\tau$ is assumed as the time that corresponds to the own and instantaneous situation of the mass. So, when $\mathbf{v}=\mathbf{c}$, the proper time $\tau$ results equal to 0 , which means a time freezing, i.e. time does not pass for a mass that would move at the velocity of light; it would mean that matter could exist in an eternity. Otherwise, If $\mathbf{v}>\mathbf{c}$, the proper time $\tau$ (the time measured at the mass position) results to be an imaginary time, i.e. it goes outside the four dimensional space of Minkowski; however, it could be assumed to exist in the Euclidic space (Figure 3) that includes an imaginary time coordinate [36].

Regarding the arrow of time, whose common image is an arrow traveling outward the space at a constant speed, it could be thank similar to the constant acceleration vector $\Gamma_{\mathrm{H}}$ of the Universe expansion [3]. In fact, out of the three types of arrow of time mentioned by reference [37], only those related to the entropy limit and the Universe expansion may coincide with such similitude.

Now, it will be intended to consider an obvious question: if light velocity (c) is, according to the Special Theory of Relativity, the maximum speed that a mass may reach, does it exist a place or circumstance in the Universe where such a limit could really been reached out? Answering this question implies some conditions. In the first place, the maximum speed $\mathrm{c}$ has been feasible, stated for matter that moves through inertial frames of reference. However, according to the proposed Hubble field, space-time is not a reference frame (rather it contains all of reference frames) and it could be assumed as expanding respect to the Big Bang coordinates $(\mathbf{r}=t=0)$, at a constant acceleration $\left(\boldsymbol{\Gamma}_{\mathrm{H}}\right)$ that causes, at long term, a higher than $\mathbf{c}$ expansion velocity.

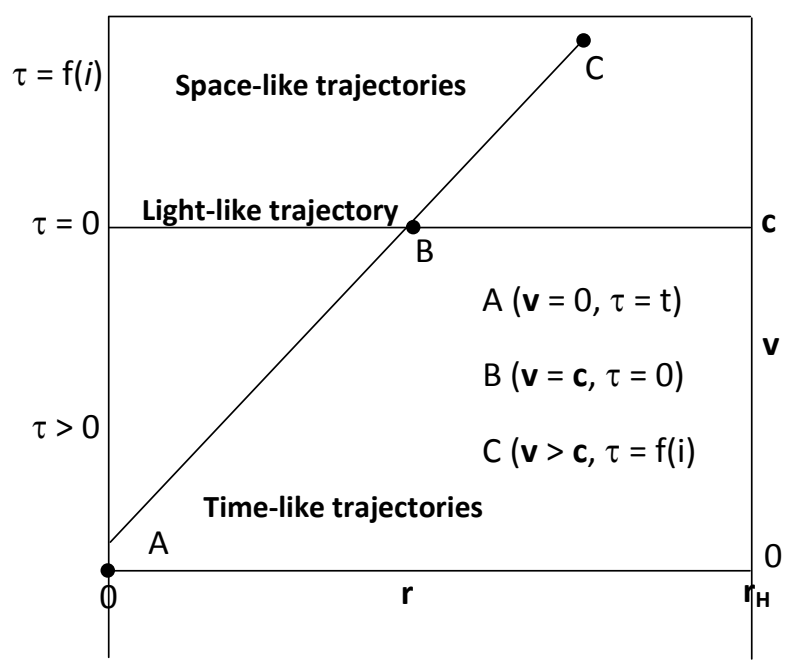

Figure 3. A trajectory in the Euclidic space diagram. 
Throughout this expansion the total masses of the Universe have been delayed due to the gravitational acceleration $\left(\boldsymbol{\Gamma}_{\mathrm{G}}\right)$ that diminishes their net velocities, so driving to the equilibrium now called as the Cosmological Principle. The spacetime expansion pulls up all matter either in frames, in co-moving coordinates and, even, if it would have a peculiar velocity. However, beyond the Hubble radius, where speeds would surpass the $c$ value, the situation should change because of the time factor. It has been shown [21] that, at the Hubble radius $\left(\mathbf{r}_{\mathrm{H}}\right)$, the expansion velocity of the space would be equal to $c$. This means that, at a distance $\left(\mathbf{r}_{\mathrm{H}}\right)$ the proper time of a mass would be 0 and, beyond, the proper time would become an imaginary function. Moreover, at high velocities, masses would have been converted in radiation by annihilation processes; so all matter near the Hubble length, in a tiny gravitational field, it should acquire the acceleration corresponding to that of the space, $\boldsymbol{\Gamma}_{\mathrm{H}}$. Then, by physical laws, how a space being coupled with imaginary time could it to be represented? Figure 3 shows a simple representation of the Euclidic space, including an assumed matter world-line from a resting state up to a velocity higher than $\mathbf{c}$.

Still pending is a meta-physical inquiry. It could be assumed that, since human soul persists after death, it must remain eternally in a space without time, i. e. similar to the actually known as the expanding Hubble sphere surface. Respect to the most outer space, with time assumed as an imaginary function, outlining such a place seems not feasible. The only argument would be that of the Religion that states, for the ethic souls, the ascent to Heaven, a space that remains imaginary for scientific minds.

\section{Conclusion}

They have been revised some of the ancient cosmological theories, from prehistory to the present time. Mention was made of those founded on ancient religions as well as those of the Middle Age and the Renaissance, developed from astronomical observations. Besides, various derivatives of the theories of relativity and quantum physics are described. An analysis is intended from the metaphysical point of view. A main conclusion is that the most probable origin of the Universe (space, time and matter) was the Big Bang. As well, they have been explored the consequences of overcoming the light velocity, beyond the Hubble sphere, in an imaginary proper time.

\section{Conflicts of Interest}

The authors declare no conflicts of interest regarding the publication of this paper.

\section{References}

[1] Lartigue, J.G. (2016) Journal of Modern Physics, 7, 1607-1615. https://doi.org/10.4236/jmp.2016.712145

[2] Lartigue, J.G. (2017) Journal of Modern Physics, 8, 2159-2166. 
https://doi.org/10.4236/jmp.2017.813131

[3] Lartigue, J.G. (2018) Journal of Modern Physics, 9, 1317-1325.

https://doi.org/10.4236/jmp.2018.96080

[4] Davies, P. (1995) L’Esprit de Dieu. Éditions du Rocher, Paris, 175.

[5] Nun-Egyptian God. www.britannica.cpm/topic/nun

[6] Marin, G. (2014) La Religión y el Dios Verdadero. Ed. Weatherblink, Mexico.

[7] Ryan, J.K. (1961) Encyclopedia Americana, 2, 114.

[8] Marshall, R. (1961) Encyclopedia Americana, 19, 272.

[9] Ancona, J.A. (1940) Cosmografía. Universidad de Yucatán, México, 53.

[10] Encyclopedia Americana (1961) Americana Corporation, New York, 752.

[11] (2018) Agustín de Hipona y la Filosofía. www.corazones.org

[12] Ancona, J.A. (1940) Cosmografía. Universidad de Yucatán, México, 68.

[13] Knickerbocker, W.S. (1940) Classics of Modern Science. F. S. Crofts, New York, 29.

[14] Maggie, W.F. (1935) A Source Book in Physics. Mc Graw Hill Book Co., New York, 92.

[15] Maggie, W. F. (1935) A Source Book in Physics. Mc Graw Hill Book Co., New York, 50.

[16] Knickerbocker, W.S. (1940) Classics of Modern Science. F. S. Crofts, New York, 138.

[17] Taylor, E.F. and Wheeler, J.A. (2000) Exploring Black Holes. Addison Wesley, New York.

[18] Bergstron, L. and Goobar, A. (2004) Cosmology and Particle Astrophysics. 2nd Edition, Springer, Berlin, Heidelberg, 59-60.

[19] Friedmann, A. and Lawden, D.F. (1982) Introduction to Tensor Calculus, Relativity and Cosmology. Dover Publications, New York, 189.

[20] Lemaitre, G. and Tolman, R.C. (1958) Relativity, Thermodynamics and Cosmology. Clarendon Press, Oxford, 362.

[21] Sartory, L. (1996) Understanding Relativity. University of California Press, Los Angeles, 299.

[22] Milne, E.A. and Tolman, R.C. (op. cit.) 364.

[23] Hawking, S.W. (1998) Historia del Tiempo. Editorial Grijalbo, México, 74.

[24] Dark Energy Task Force Report (2006).

[25] Isham, C.J. (2002) La creación del Universo como un proceso cósmico. In: Física, Filosofía y Religión, Observatorio Vaticano, Roma, 457.

[26] Hawking, S.W. (1998) Historia del Tiempo. Editorial Grijalbo, México, 182.

[27] Penrose, R. (2010) Cycles of Time. Bodley Head, London, 137. http://www.bodleyhead.co.uk

[28] Tipler, F. (1997) The Physics of Immortality. Random House, New York, 353.

[29] Gleisser, M. (2013) The Origin of the Universe. https://www.npr.org/sections/13.7

[30] Hawking, S. (1998) Historia del Tiempo. Editorial Grijalbo, México, 224.

[31] Polkinhorne, J. (2002) El Mundo Cuántico. In: Física, Filosofía y Teología, El Observatorio Vaticano, 377.

[32] El Papa Francisco apoya la Teoría del Big Bang. Diario El Clarín, Buenos Aires.

[33] Riess, A., et al. (1998) The Astronomical Journal, 116, 1009-1038. 
[34] Davies, P. (1995) L’Esprit de Dieu. Éditions du Rocher, Paris, 175.

[35] Sagrada Biblia-Génesis, trad. F. Torres (1980), Servagroup Ed., Madrid, ch. II, v. 7, 17.

[36] Hawking, S. (1998) Historia del Tiempo. Editorial Grijalbo, México, 179.

[37] Hawking, S. (1998) Historia del Tiempo. Editorial Grijalbo, México, 191. 